\title{
Women seafarers' health and welfare survey
}

A joint initiative of the International Maritime Health Association (IMHA), International Seafarers' Welfare and Assistance Network (ISWAN), International Transport Workers' Federation (ITF) and Seafarers Hospital Society (SHS)

\section{Suzanne Stannard ${ }^{1}$, Caitlin Vaughan ${ }^{2}$, Olivia Swift $^{3}$, Georgina Robinson ${ }^{4}$, Syed Asif Altaf ${ }^{5}$, Alison McGarry ${ }^{6}$}

\author{
${ }^{1}$ Medical Adviser, Norwegian Centre for Maritime Medicine/International Maritime Health Association, Bergen, Norway \\ 2Project Manager, International Seafarers' Welfare and Assistance Network, London, United Kingdom \\ ${ }^{3}$ Lecturer in Anthropology, Goldsmiths, University of London, United Kingdom \\ ${ }^{4}$ Health Development Manager, Seafarers Hospital Society, London, United Kingdom \\ 'International Transport Workers' Federation, London, United Kingdom \\ ${ }^{6}$ Women Transport Workers Coordinator, International Transport Workers' Federation, London, United Kingdom
}

\begin{abstract}
Background: This is a collaborative study from the International Maritime Health Association, International Seafarers' Welfare and Assistance Network, International Transport Workers' Federation and the Seafarers Hospital Society. The aim of the study was to look at the health and welfare needs of women seafarers and how organisations can best make or campaign for improvements to the health information and services available to women seafarers.

Materials and methods: A pilot study was conducted in July 2014 and following review of the data and revision of the questionnaire the study was launched in December 2014, running until the middle of March 2015. Results collected from the survey are also supported by qualitative data obtained from two focus groups run during February and March.

Results: 595 responses were received from a range of nationalities, ages and positions on board ships. The findings suggest that joint/back pain, stress/depression/anxiety and headache seem to be the most common symptoms reported by women seafarers and that $55 \%$ felt that they are related to their work. $48 \%$ state that they have problems with seeking medical care and offer suggestions to improve this. Routine wellness checks, nutrition and information on joint and back pain are the main areas that women seafarers stated health screening/services/information would be most useful to improve their health and wellbeing. They suggested this could best be received directly from health professionals, or alternatively by reading leaflets or from online websites/an app. Significantly $37 \%$ of women seafarers also stated that they do not have access to sanitary bins within the toilet and $18 \%$ say that sexual harassment is an issue.

Conclusions: The responses received highlight a small number of areas where relatively simple and low-cost interventions might improve the health and welfare of women seafarers. Specifically these include the production and appropriate, distribution of gender - specific information on back pain, mental health and nutrition in addition to gynaecological complaints, to all women seafarers; the introduction of means for disposing of sanitary waste for all female crew on all ships and the improved availability of female specific products e.g. sanitary products in port shops and welfare centres worldwide. Additional work is needed to investigate these areas more fully and to look at the issue of confidence in medically trained staff, medical confidentiality and sexual harassment. Any further work and interventions will require the support of all of the main stakeholders and we plan a briefing meeting to publicise the findings to date and to identify support for further work in this area.
\end{abstract}

(Int Marit Health 2015; 66, 3: 123-138)

Key words: women seafarers' health and welfare needs 


\section{BACKGROUND}

This research project was conducted during 2014-2015 , run jointly by representatives from International Maritime Health Association (IMHA), International Seafarers' Welfare and Assistance Network (ISWAN), International Transport Workers' Federation (ITF) and Seafarers Hospital Society (SHS). No funding has been sought for the project to date.

The project has been based around an online survey of women seafarers, supported by focus groups. It explores women seafarers' health and wellbeing (including issues of sexual harassment) at work and how they might be improved.

The project grew out of a concern that medical handbooks and other literature aimed at women seafarers are outdated and fail to provide a gendered perspective to health or to consider health and related issues that are specific to women $[1,2]$. Hence at a time that we are working to increase the recruitment and retention of women seafarers we may not be meeting their specific health and welfare needs.

\section{WOMEN SEAFARERS - EXISTING RESEARCH}

A modest body of research into women seafarers exists, much of which is referenced in this paper. There is the scope and need for further research in this area in order to meet the needs of both individual women seafarers and those of the industry that benefits from their recruitment and retention.

Research reveals that women continue to face discrimination [3]:

- Some countries continue to ban women from enrolling on nautical courses. Some women who enrol without issues still report that staff within maritime education and training institutions seems averse to their presence.

- Employers are often reluctant to take on women cadets/ /qualified seafarers, partly because of a misled belief that women work at sea for less time than men (see below).

- Women are often paid less than men doing the same work.

- Some employers are reluctant to promote women to more senior ranks.

- Women may be denied the facilities/equipment available to men on board.

- Women seafarers may face bullying, sexual harassment and/or violence at sea.

- Women have to prove themselves that bit more than incoming male crew by working to the limits of their endurance [4-6].

However there is evidence to demonstrate that retention of seafarers is not a gender issue:

- 'There are insufficient numbers of women seafarers to allow for accurate statistical comparisons of male and female retention rates within the industry. However, despite the perception in some quarters of the industry that women seafarers stay at sea for shorter periods of time than their male colleagues, our evidence suggests that the retention rates of women coming from OECD [Organisation for Economic Co-operation and Development] countries, where most women in the marine sector are employed, are broadly comparable' [3].

- $66 \%$ of Nautilus' female members work on ships for more than 6 years and 19\% have onboard tenures of over 15 years (NUMAST 2000 survey).

- 'Given that dissatisfaction with prolonged separation from home and family has been reported as one of the most common reasons for (male) seafarers abandoning a career at sea (Telegraph 1999), the issue of retention applies to both male and female seafarers and should be addressed by the industry as such [4-9].

- 'Having women as part of the crew can help reduce the sense of isolation felt by many seafarers (and hence supports overall retention)' [10].

- Women's participation in the maritime sector is shore-as well as sea-based: shore-based roles (including management) requiring sea experience often appeal to former women seafarers [11].

\section{WHAT IS BEING DONE TO INCREASE WOMEN'S PARTICIPATION IN SHIPPING?}

The United Nations has been promoting women's employment and the integration of women into all levels of political, social and economic development since the 1970s. As part of this, the International Maritime Organisation (IMO) produced a strategy for the integration of women in the maritime sector in 1988 known as 'Women in Development'. This programme has concentrated on equal access to maritime training through both mainstream programmes and gender-specific projects [3] and has been followed by two, four-year 'recruitment and sensitisation' programmes. The IMO has established seven regional associations for women to share information and advice in the maritime sector, which cover Africa, Asia, Latin America, the Pacific Islands [12], and Caribbean [13]. There have been two further commitments concerning women seafarers, made by the ILO and IMO. The resolution adopted by the Joint Maritime Committee at its $29^{\text {th }}$ Session, 22-26 January 2001, in Geneva, and the resolution adopted by the IMO at its $21^{\text {st }}$ Session in 1999 , reiterated at the $50^{\text {th }}$ Session of its Technical Cooperation Committee, 21 June 2001, called for a more active role to be taken in promoting the integration of women into the industry. In particular, the ILO's Joint Maritime Committee has called for more research to be conducted on women seafarers (ILO, 2001; IMO, 1997, 2001) [3]. 
The IMO's promotion of women's participation is not about supporting women per se, or supporting women at the expense of men - 'We're not supporting women, we're supporting the maritime sector and its human beings' said Pamela Tansey, Senior Deputy Director of the IMO. Evening out the gender imbalance is good for the industry as well as individual women, especially since 'companies employing women consistently referred (refer) to the quality and commitment of female staff and the general benefits of having a more gender-balanced shipboard workforce' [3].

Belcher et al. [3] provide an overview of the position and actions of ship owners, ship managers, employer associations, governments, international organisations, unions and maritime education and training institutions regarding women seafarers. They report, for example, few unions having equal opportunity policies or any policy specifically relating to women although there are exceptions. Nautilus runs a women's forum and in 1998, the ITF established a Women's Committee to advise its Executive Board on gender-related matters. The ITF also has an anti-discriminatory policy, which was introduced in 1999 [14].

\section{SO WHAT ARE THE 'CURRENT’ NUMBERS OF WOMEN SEAFARERS?}

- $1-2 \%$ of the world's 1.25 m seafarers are women, serving on some 87,000 ships (IMO 1992: This data forms the basis of a 2003 study commissioned by the International Labour Office and conducted by academics [3] from the Seafarers' International Research Centre at Cardiff University. There is a clear need for more recent global data on women seafarers.).

- The ITF estimates its female seafaring membership to be 23,000 worldwide [15] (corresponding to approximately $1 \%$ of its seafarer membership).

Among a group of eight European countries (Belgium, Denmark, Finland, Germany, Italy, Norway, Sweden and the United Kingdom [UK]), the average proportion of women in the total seafaring workforce between 1997 and 2001 was found to be $9.15 \%$, although the relatively high number of Swedish and Danish women and the very low number of Italian women seafarers seriously distort this average. In other parts of the world, women's representation in the seafaring workforce varies greatly from country to country. For example, their share of the workforce is $5 \%$ in Indonesia and Latvia, about 3\% in Australia and 0.5\% in New Zealand. In 1998, India reported that the country had 43,000 registered seafarers, of whom only three were women. In the Philippines only 225 seafarers out of 230,000 seafarers appear on the national seafarers' register for 1983-1990, while in Brazil women comprise $1.1 \%$ of the workforce [16]. More recent studies suggest that there is still a long way to go [17]. The Women Seafarers' Health and Welfare Survey project has not, as yet, collated recent government/union/other figures bar for the Philippines. Here, government figures show women to comprise 29\% of new-hire seafarers in 2010 [18]. This is a striking and encouraging statistic.

According to Belcher et al. [3] for the International Labour Organisation (ILO) as referenced above:

- $94 \%$ of women seafarers are employed on cruise ships $(26 \%)$ and ferries (68\%), often on vessels flying Flags of Convenience;

- women form $17-18 \%$ of the seafaring workforce in the cruise sector whilst $6 \%$ of women seafarers work on cargo ships (typically those at the higher end of the standard spectrum);

- $7 \%$ of officers are women (cf. $42 \%$ of men) and most women work as ratings as service staff on passenger ships. Of this latter group:

- $51.2 \%$ come from OECD countries;

- 23.6\% from Eastern Europe;

- 9.8\% from Latin America and Africa;

- $13.7 \%$ from the Far East;

- 1.7\% from South Asia and the Middle East.

It is not clear from these figures whether major supply countries such as Indonesia and the Philippines fall under South Asia. The same ILO publication also states the average age of women working on cruise ships as 31.5 years. There is little in the way of additional data available looking at the age of women seafarers in general and across the different sectors.

\section{MATERIALS AND METHODS}

The IMHA, ISWAN, ITF and SHS Women Seafarers' Health and Welfare Survey was an online survey (see Appendix 1) running between 2014 and 2015 that attracted 595 respondents. The survey was promoted online through social media sites with large seafarer followings and at seafarer centres around the world; $90 \%$ of participants completed the survey online. The remaining $10 \%$ completed paper copies which they received from welfare workers or union affiliates in seafarer centres and during maritime events around the world.

Questions were selected based on the experience of the authors and following review of the pilot study conducted in 2014 - also an online survey - which received around 100 responses. It was decided that a number of the questions in the pilot survey should be removed or adapted for the main survey. This was because of reconsiderations about the effectiveness of a question's wording or because it was no longer useful/relevant.

In addition to the survey, two focus groups of ten women working as ratings on cruise ships were held in Cebu by 


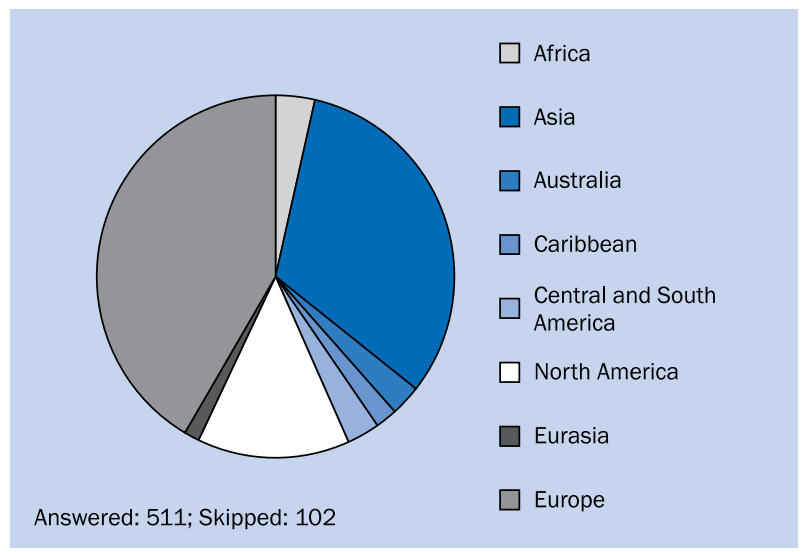

Figure 1. Nationality

two union representatives. Participants worked in either catering or accommodation and were all under the age of 40. Group leaders asked participants questions about their answers in the survey and encouraged interactive discussion. Answers were noted by focus group leaders and sent to the project group for further analysis alongside participants' completed surveys. See Appendix 2 for focus group questions.

\section{RESEARCH FINDINGS AND DISCUSSION}

\section{AGE GROUP}

$73 \%$ of respondents were under the age of 40 years (41\% aged $19-30$ years and $32 \%$ aged $31-40$ years) with $18 \%$ aged $41-50$ years, $8 \%$ aged $51-60$ years and just two respondents over 60 years.

\section{NATIONALITY}

$43 \%$ of respondents were from Europe and Eurasia (Russia and Turkey); 32\% of respondents were from Asia; 14\% from North America and the remaining 11\% from Africa, Australia, Caribbean and Central and South America. Most respondents came from Northern Europe (with 113 from the UK - partly a reflection of the contacts of the UK-based research team), followed by Southeast Asia (110 from the Philippines). There is a marked increase in the proportion of respondents from non-'embedded' [16] maritime nations among younger seafarers (those under the age of 40 years), which suggests that the recruitment of women from newer supply nations has increased in recent years (Fig. 1). Embedded maritime nations' replaces the more familiar term 'traditional maritime nations' to provide a more accurate description of modern international shipping. Countries such as... the Philippines have been involved in maritime commerce for many centuries and are, therefore, unquestionably, traditional maritime nations. However, only since the Second World War [has the Philippines]... developed [a] highly organised shipping industry infrastructure... comparable to those of Europe and Japan, where developments began 50 to 100 years earlier and so can be described as having become "embedded [16].

\section{SECTOR}

As shown in the Figure 2, 40\% of respondents work on cruise/passenger ships, which is surprisingly low given the ILO's 2003 figure of $94 \%$ cited above. This might be related to the survey being distributed out of season for European cruise ports. The answers under 'other' include: yachts, military vessels, education/training vessels, tug boats.

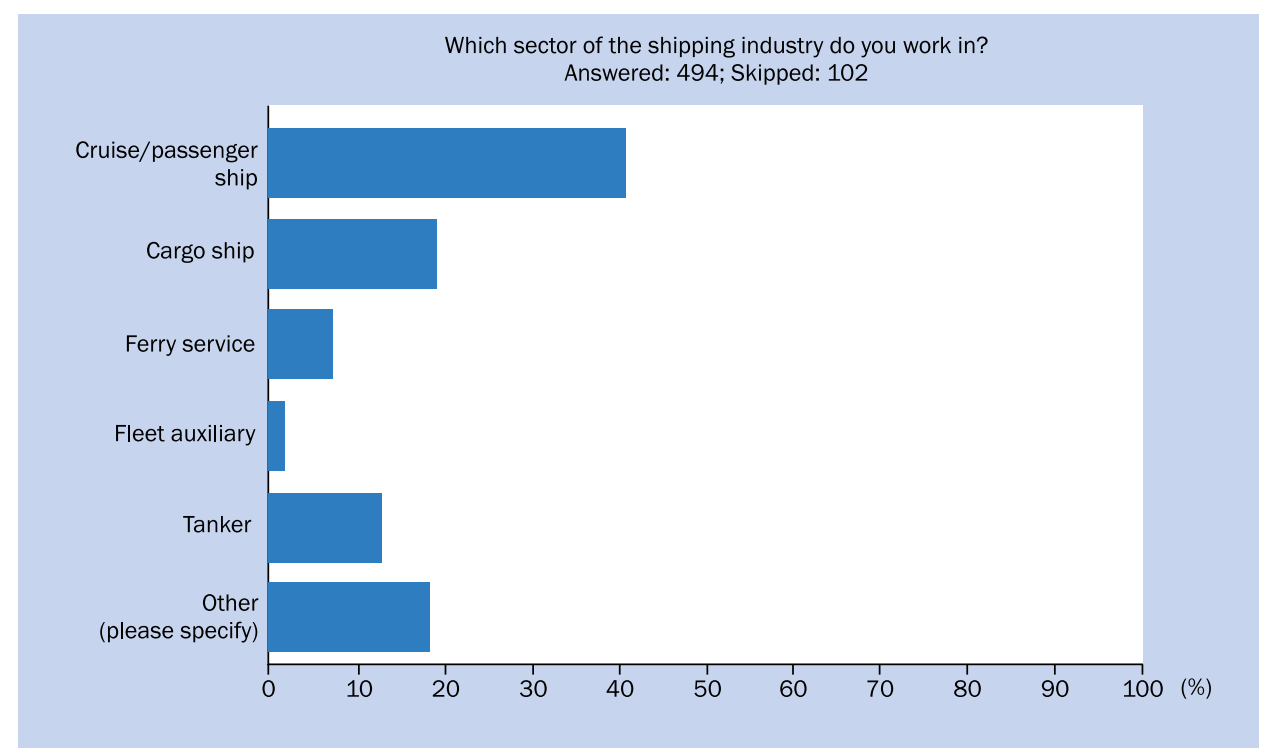

Figure 2. Sector of the shipping industry 


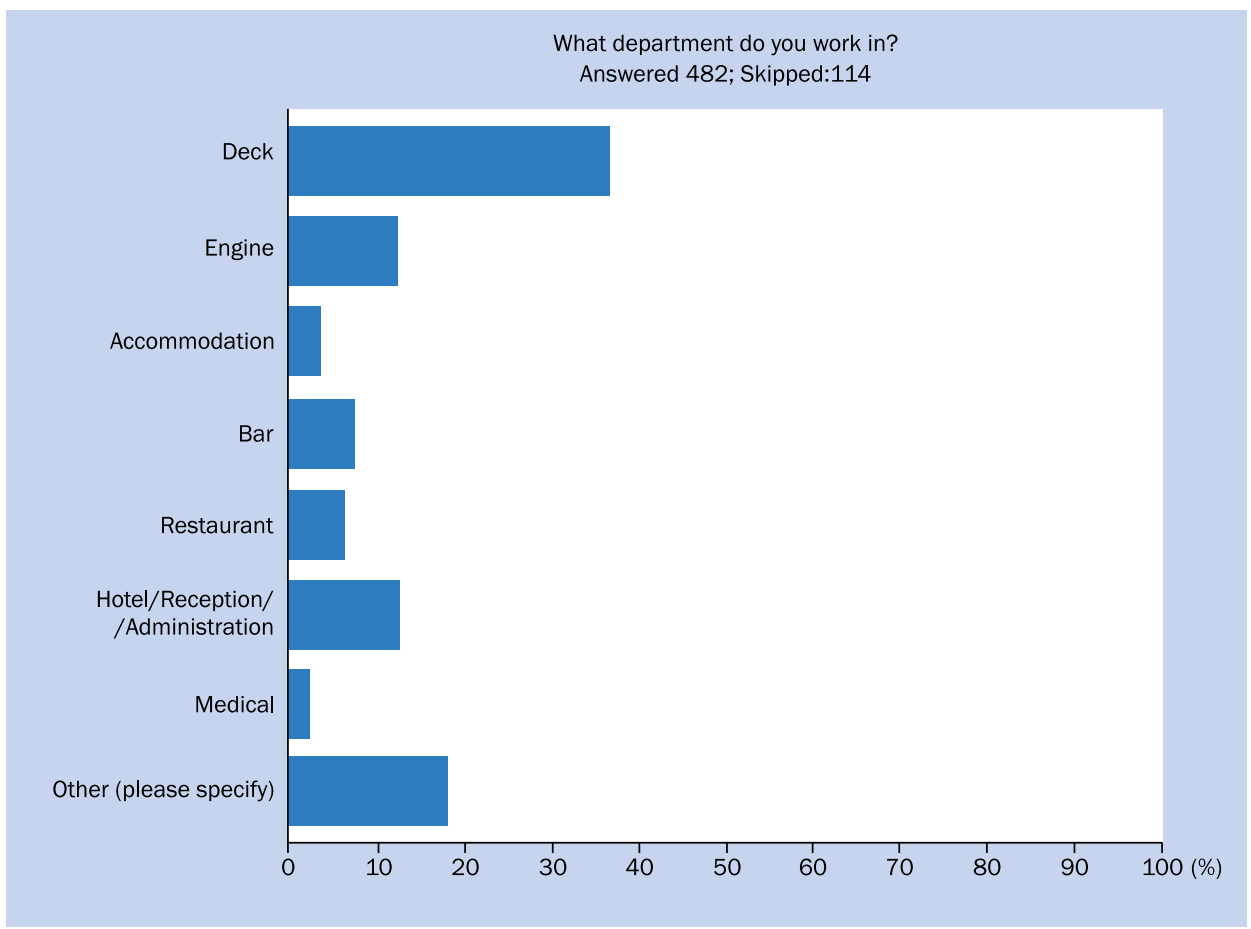

Figure 3. Work department

As mentioned above, $73 \%$ of respondents are under the age of 40 years. On further cross analysis of the data it was seen that the number of respondents in this age range was similar for those working on cruise ships (71\%) and cargo ships (77\%), but considerably higher for respondents working on tankers (85\%) and fleet auxiliary (100\%). These figures are in line with those from the ILO mentioned above. In contrast, only $54 \%$ of respondents working on a ferry service were under the age of 40 years.

$42 \%$ of cruise ship workers were from the Philippines (75\% of all Filipino respondents work on cruise ships). Although the largest proportion of respondents working on cargo ships were from Asia, only $20 \%$ of all Asian respondents were working on cargo ships. $75 \%$ of ferry workers were from Europe. $43 \%$ of those working on tankers were from Europe and 23\% were from North America.

\section{DEPARTMENT}

Over 35\% of respondents work in the Deck department, as shown in the Figure 3. The departments listed under 'other' included: 'entertainment', 'shops' and 'housekeeping'. The age groups and nationalities represented vary across departments.

Most respondents working in accommodation were from Asia (89\%) and all respondents but one were under the age of 40 years. A slightly lower proportion of those working in a bar were from Asia (63\%) and $76 \%$ of all bar workers were under the age of 40 years. Just over half of those working in the Deck department were from Europe/Eurasia (57\%), $18 \%$ are from North America and $17 \%$ are from Asia. $87 \%$ of those working in the Deck department were under the age of 40 years. Just over half of those working in the Engine department were from Asia (52\%); followed by $27 \%$ from Europe. $82 \%$ of this group were under the age of 40 years.

The only regions represented in the Restaurant department were Asia (54\%); Europe (34\%) and the Caribbean $(12 \%)$, and $86 \%$ were under the age of 40 years. $37 \%$ of Galley workers were from North America, closely followed by respondents from Asia (32\%). In comparison to the other departments, the proportion of respondents under the age of 40 years working in the Galley is much smaller at $52 \%$. Asia and Europe were the largest groups represented among respondents working in the Hotel department (44\% and 34\% respectively). $59 \%$ of the whole group was under the age of 40 years. A total of eight respondents work in the Medical department; 5 (62.5\%) of these were from Europe, with one from each of the Caribbean, Africa and Asia.

\section{RANK}

Although just $7 \%$ of women are officers according to the ILO 2003 data, more than half of our respondents said they were officers. This may be because officers are more likely to have internet access to participate in the survey or because of the relatively low numbers of cruise workers and workers from Asia who completed the survey. $60 \%$ of the officers selected 'cargo', 'tanker' or 'other' as the type 


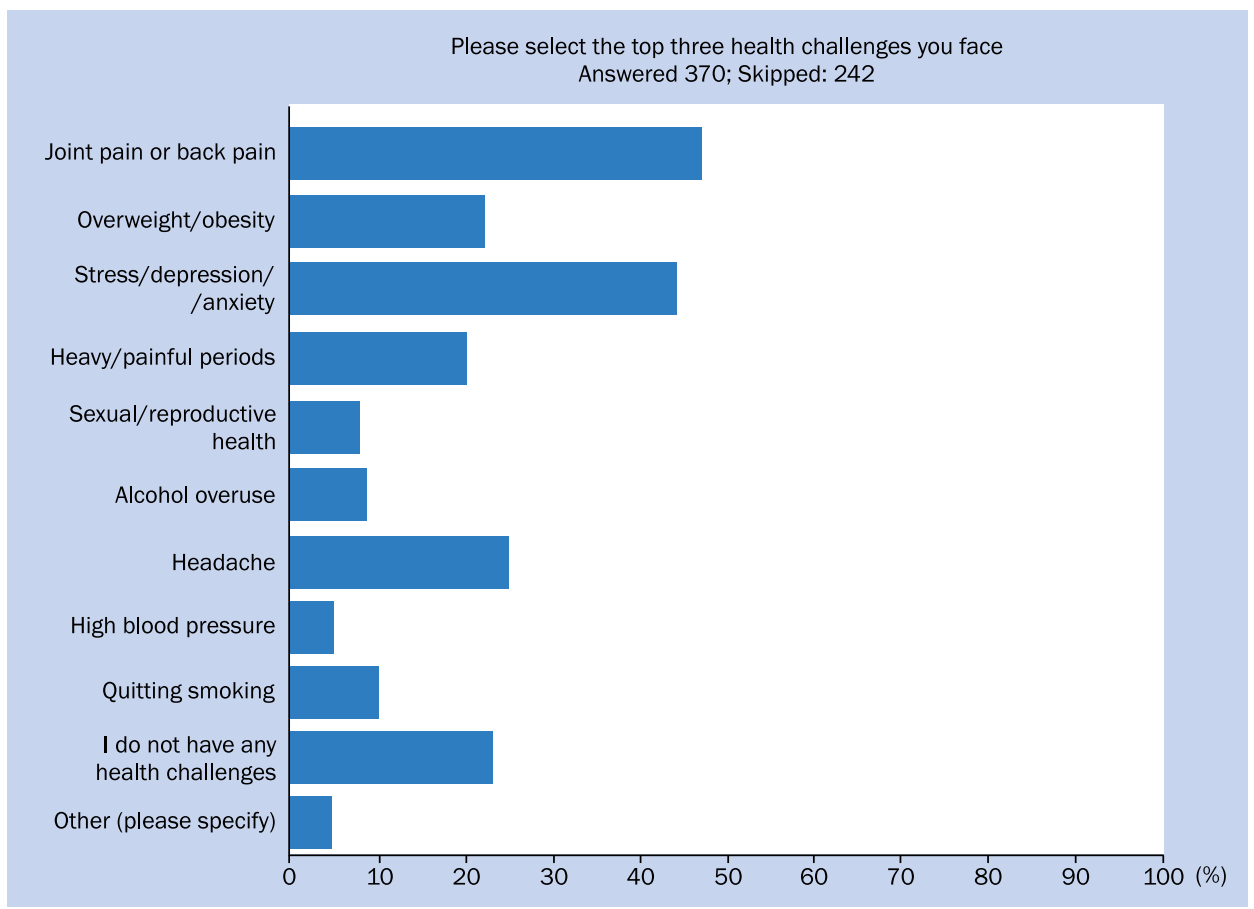

Figure 4. Top health challenges

of vessel on which they work. $63 \%$ of crew/ratings work on cruise ships and over $40 \%$ of respondents from crew/ratings were $31-40$ years of age. Nearly $50 \%$ of officer respondents were under the age of 30 years. Respondents from Asia make up the largest proportion of crew/ratings (44\%) and most respondents from Asia were crew/ratings (67\%). This is a significant finding as only $32 \%$ of all respondents were from Asia. 31\% of officer respondents come from non-OECD countries, with the Philippines providing the largest number from this group at $8 \%$. The Caribbean has the largest proportion of respondents who were crew/ratings at $90 \% .43 \%$ of all respondents were from Europe, but only $32 \%$ of crew/ /ratings were from Europe. 53\% of officers were from Europe, and $63 \%$ of respondents from Europe were officers. Almost $70 \%$ of respondents from North America were officers.

\section{SUPERVISORY ROLE}

Nearly $70 \%$ of respondents said that supervision of others is part of their role. $27 \%$ of these responses come from the UK and just over 10\% from the United States. None of the respondents who said they had a supervisory role came from India or Southeast Asia.

Respondents who answered 'yes' to this question were fairly scattered across shipping sectors but the largest proportion worked on cruise ships (33\%) and 45\% said they work in the Deck department. Over $50 \%$ of the respondents who said they do not have a supervisory role work on cruise ships, mostly in entertainment or as hotel staff. Nearly 35\% of these respondents were from Asia, 10\% were from Europe and just less than 5\% were from South America. Results were fairly consistent across all age groups.

\section{TOP HEALTH CHALLENGES}

Respondents were asked to select the three main health challenges affecting them (Fig. 4). The top answer to this question was joint/back pain with nearly half of respondents selecting this option, closely followed by 'stress/depression/ /anxiety' (43\%). More ratings (56\%) than officers (40\%) reported 'joint/back pain'. 'Stress, depression and anxiety' was the top choice for officers although a similar number of ratings and officers selected it. It is worth noting that more than 100 participants chose to leave the survey at the start of this question, possibly because they thought the survey was a repeat of a pilot survey they had already completed, or because they found it too time-consuming, demanding, or they may have had concerns about the confidentiality of their responses.

$75 \%$ of respondents under the age of 40 years selected 'joint/back pain' as a top health challenge, and it is the top health challenge for all age groups except 51-60 year olds. $56 \%$ of respondents from this age group selected 'stress, depression and anxiety' and $44 \%$ selected 'joint/back pain'. This can be compared to the respondents under the age of 50 years where $42 \%$ selected 'stress, depression and anxiety' and 49\% selected 'joint/back pain'. The 51-60 years age group also has a higher proportion of respondents who selected 'overweight/obesity' (36\%). This was only an issue for $20 \%$ of those under 50 years. 


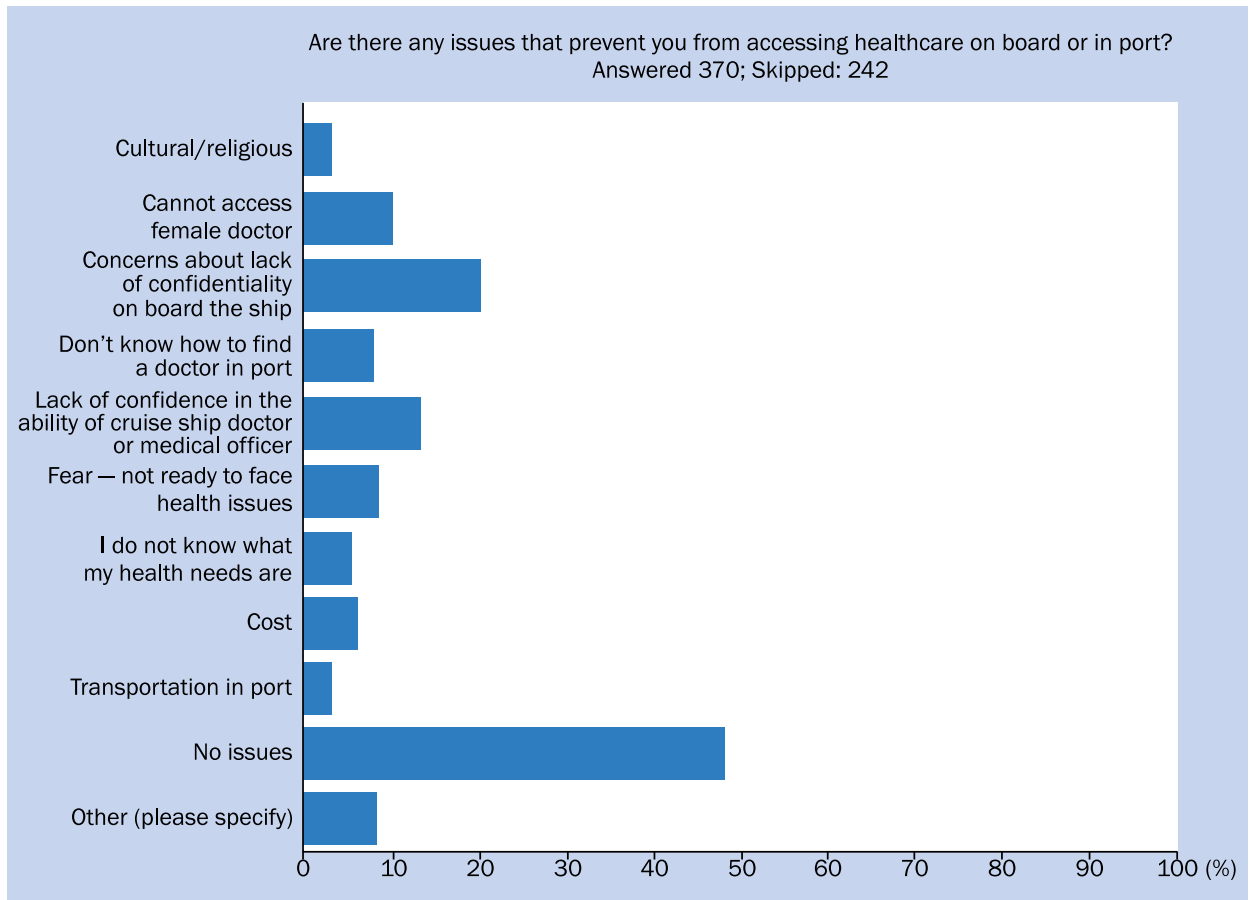

Figure 5. Issues preventing access to healthcare

Although joint/back pain was the top issue overall, it does not appear to affect as many respondents working on cargo ships or tankers in comparison to those working on cruise ships. Instead, stress/depression/anxiety was the top health challenge in both of these sectors. This difference could firstly be explained by the much greater number of ratings in the cruise sector answering the survey. In each of the other sectors there were a higher number of officers than ratings, but only $28 \%$ of respondents working on cruise ships were officers. In addition, ratings on cruise ships were largely working in service roles as part of accommodation and restaurant departments where they spend long periods on their feet and often have to carry heavy trays or luggage.

There was an equal split in the number of respondents from Africa, Australia, Europe and North America who chose 'joint/back pain' and 'stress, depression and anxiety'. For respondents in the Caribbean and Asia, 'joint/back pain' was the top issue. $56 \%$ of respondents who selected 'joint/ /back pain' also selected 'stress, depression and anxiety'. These findings correlate with those in a recent ITF survey of seafarers and affiliates where $7.5 \%$ of the 695 respondents were women [19].

\section{HEALTH CHALLENGES RELATED TO WORK}

Respondents were asked whether they felt that any health issues they experienced were related to their work. Over $55 \%$ of respondents felt that this was the case. These numbers were very similar for both officers and ratings. The number of respondents who answered 'yes' to this question was much higher for those who said that joint/back pain is an issue for them, at almost $75 \%$ and even higher for those who selected 'stress, depression and anxiety', at 78\%. Three quarters of those struggling with weight or obesity problems said they linked their health issues to work and almost $70 \%$ suffering from headaches felt their challenges were work-related. Results were fairly consistent across age groups and were similar for both ratings and officers.

It is important to note that respondents were not asked which specific health issues they felt were related to work, and as respondents were asked to select their top three health challenges, we cannot make a definite assertion about the link between a particular health challenge and a respondent's role on board. However, in the focus group sessions the following issues were reported in connection with joint/back pain:

- having to carry heavy trays while serving food/drinks;

- hallways too narrow to use trolleys;

- on some newer ships there is only one central galley, which adds to the burden of the restaurant personnel as they have to carry trays on escalators and through elevators between several decks;

- carrying passenger luggage to cabins;

- pressure to finish housekeeping work quickly (carrying linens in and out, putting linens back on beds).

\section{ISSUES PREVENTING ACCESS TO HEALTHCARE}

As shown Figure 5, respondents were asked to identify any issues that they felt affected their ability to access 


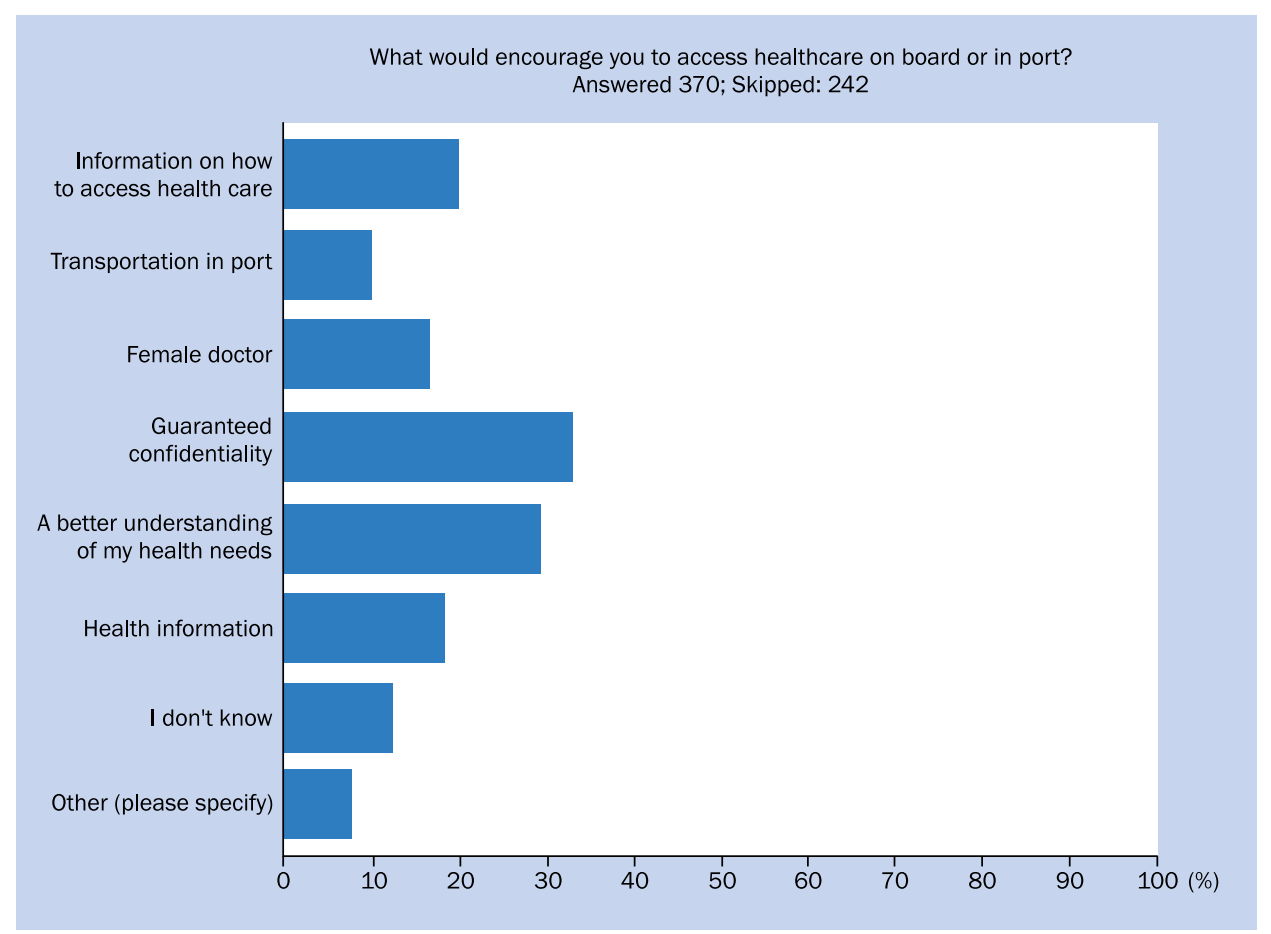

Figure 6. Factors that would encourage seafarers to access healthcare

healthcare at sea or in port. Just under half of respondents said that they experienced no such barriers. For those who did experience issues, "concerns about lack of confidentiality' was selected by $21 \%$ of participants. Answers did not vary significantly between ratings and officers or across age groups. In focus group discussions, concerns were raised about job security, in particular whether seafarers would be rehired if diagnosed with particular medical conditions.

Almost all focus group participants said they self-diagnose and use over-the-counter medicines and antibiotics from home as well as herbal and alternative medicines and this is reflected in the literature available [20, 21].

The only significant finding when looking at responses according to nationality is that $40 \%$ of respondents who said they lacked confidence in the ability of their cruise ship doctor or medical officer were from Asia (cf. 32\% of all respondents are from Asia). On further analysis we found that $26 \%$ of those who lacked confidence in their doctor or medical officer's ability worked on cruise ships, $12.2 \%$ on tankers and $3 \%$ on cargo ships. Whilst this may be in part due to the wording of the question it is an area of concern. Other responses were fairly consistent across sectors apart from 'concerns about lack of confidentiality' which was selected by $37 \%$ of respondents working on tankers (it was selected by $23 \%$ of cargo ship workers, $19 \%$ of cruise ship workers and $12.5 \%$ of ferry workers).

\section{FACTORS THAT WOULD ENCOURAGE SEAFARERS TO ACCESS HEALTHCARE}

Respondents were then asked whether there were any particular factors that would (or that do already) encourage them to access healthcare, as illustrated Figure 6. The most common answer to this question was 'guaranteed confidentiality' closely followed by 'a better understanding of my health needs'. Answers did not vary significantly across age groups. More port time was mentioned under 'other'.

Focus group participants reported the following factors which may help to relieve issues accessing healthcare:

- being able to see a doctor whilst on duty;

- doctors of both genders;

- more job security - knowing that you will be rehired even if you are sent home;

- easier access to a shore side specialist for a second opinion if the onboard doctor is not able to help;

- doctors of both genders.

\section{HEALTH INFORMATION AND SERVICES VALUED BY WOMEN SEAFARERS}

Respondents were asked to select which types of health screenings, information and services they felt they needed to maintain 'good health'. As shown below, more than half stated that they would value routine wellness checks whilst more than a third would like information about nutrition. There was a roughly even spread of respondents wanting 


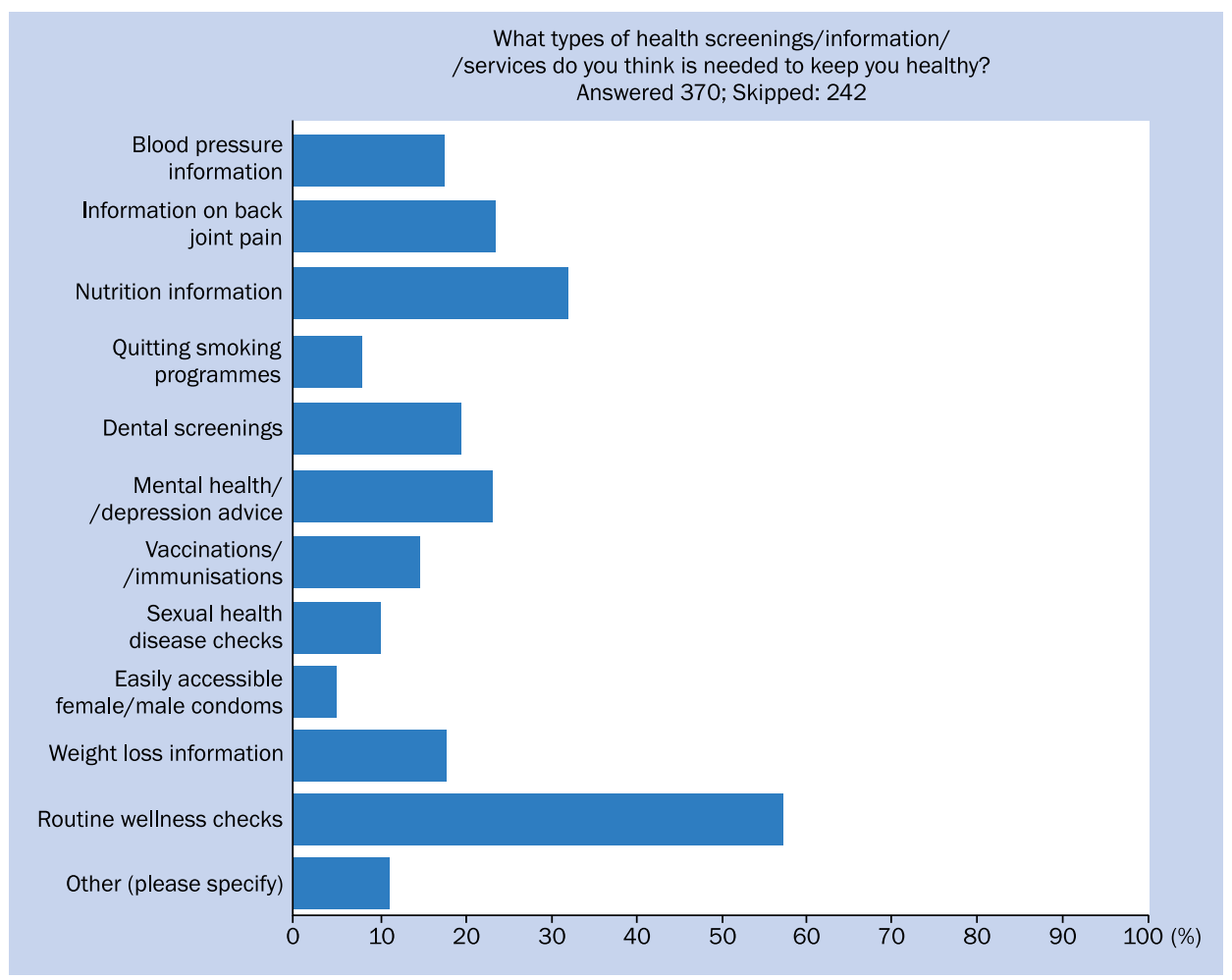

Figure 7. Health information and services valued by women seafarers

more nutritional information across regions except Central and South America where 53\% of respondents selected this option. A similarly even spread across region was found for respondents requesting information on joint/back pain, although it may be worth noting that more respondents from Africa and the Caribbean said they needed information on joint/back pain than nutritional information.

Respondents in need of information on mental health and depression vary between $12 \%$ and $20 \%$ across regions except Australia where $43 \%$ of respondents said they were in need of this information. There are not many differences across the age groups under 50 years, but in the 51-60 years age group, the most popular answer choices after 'routine wellness checks' were 'information on quitting smoking' and 'weight loss information', which were both selected by $16 \%$ of respondents in this age group (Fig. 7).

Focus group participants were asked what 'good health' meant to them. Answers were as follows:

- having a full day off to rest (e.g. 1 day per month);

- more privacy; on older ships, 4-6 crewmembers share cabins and it can be hard to get the necessary rest someone is always coming or going, showering, on the phone, reading etc.;

- more diversional activities such as physical exercises, zumba, yoga, film showing etc.;

- women support groups where you can reach out for help from someone you can relate to;
- alcohol in moderation to relieve stress and socialise;

- having their spiritual needs met could help to relieve stress.

\section{PREFERRED MEDIA FOR LEARNING ABOUT HEALTH}

Over $50 \%$ of respondents selected 'listening to health professionals' but 'online, Apps, websites' was a popular choice too with nearly $45 \%$ of respondents selecting this medium. Note that more than one choice could be selected. Most focus group participants said they valued booklets/brochures. Some pointed out internet access can be expensive and if usage is limited, they would prefer to use it to contact family rather than to access health information. Short films shown on board and lectures were also mentioned, specifically about HIV and suicide prevention.

\section{ACCESS TO SANITARY BINS ON BOARD}

Nearly $40 \%$ of respondents said they do not have access to a sanitary bin on board; however, there was notable variation across rank and sector. $53 \%$ of officers reported not having access to a sanitary bin compared to only $23 \%$ of ratings. The differences between sectors are also quite striking. In the cruise sector, nearly $85 \%$ of participants indicated having access to a sanitary bin on board, whilst the figure for those working on ferries was slightly lower 
at $63 \%$. There were much lower levels of access on cargo ships and tankers with only $38 \%$ and $27 \%$ (respectively) answering 'yes' to this question.

We offered a further comment text box for this question. Out of the 38 respondents (10\% of the total respondents) who left a comment:

- 5 said they did not want sanitary bins on board or that it was not an issue;

- 13 felt strongly that there should be a solution in place for the disposal of sanitary items;

- 19 did not express an opinion but left information about the situation on their ship;

- 2 felt that sanitary protection should be provided on board as well as a confidential disposal method.

\section{SEXUAL HARASSMENT}

Just over $17 \%$ of respondents in the main survey said that sexual harassment is an issue for them. This contrasts sharply with the results of our pilot survey of 100 women seafarers where just under $50 \%$ of respondents reported experiencing sexual harassment at sea. A possible reason for this difference in findings is that many more respondents to this survey appear to be in a supervisory role in comparison to the pilot survey and it is generally assumed that sexual harassment is more commonly a problem for those with less power in the workplace. We cannot make direct comparisons or draw definitive conclusions about this because the pilot survey did not include a specific question about rank or supervisory responsibilities, as was included in this survey. However, a question was asked about position on board and around $30 \%$ of respondents identified themselves as officers, which is much lower than the number of officers participating in this survey (51\%). It is worth noting that in the main survey, results were similar for both officers and ratings as well as for respondents who have a supervisory role compared with those who do not. Given the significant number of respondents in the pilot survey who had stated that sexual harassment is an issue, we looked further into the responses in both surveys. In the main survey sexual harassment was experienced by some in all age groups but those in the 19-30 years group were most affected ( $27 \%$ of that age group), followed by $31-40$ year-olds at $11 \%$. Comparing the age groups in both surveys it is clear that sexual harassment is largely, although not exclusively, an issue for younger women seafarers and the results are similar in the two surveys. The results of the pilot survey and the main survey do vary in the sectors employing the women for whom sexual harassment is an issue (Fig. 8).

It is very difficult to explain the mismatch in the percentage of women raising sexual harassment as an issue between the two surveys. It is also difficult to explain why the sectors these women work in vary so markedly from

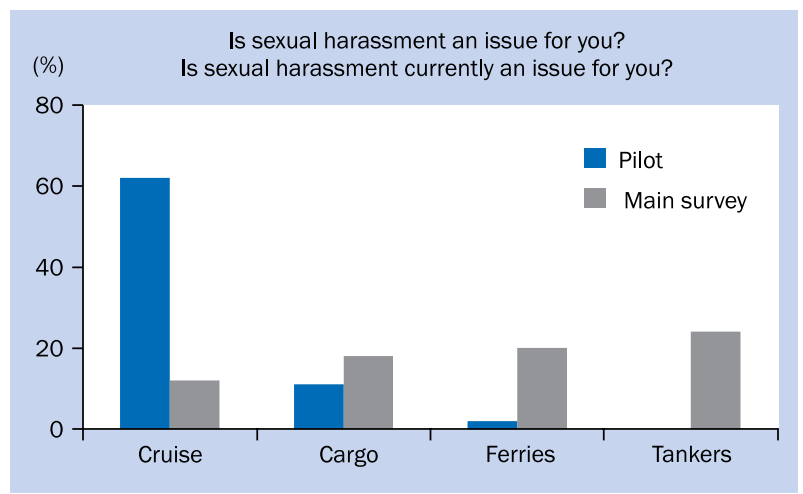

Figure 8. The distribution of respondents (\%) across shipping sector who said that sexual harassment is an issue for them

the pilot to the main survey. It is worth noting, however, that there was a slight difference in wording between the questions in each survey, as indicated above.

Respondents were given the option to leave a comment and there were a number of points raised. Of the respondents who answered 'No' to this question:

- 8 said that sexual harassment had been an issue in the past;

- 2 said they were currently aware of others who were affected;

- 3 said that harassment was not an issue for them but discrimination and bullying were.

\section{CONCLUSIONS AND RECOMMENDATIONS}

Whilst it is difficult to comment on how representative the sample is of all women seafarers, the responses received do highlight a small number of areas where relatively simple and low-cost interventions might improve the health and welfare of women seafarers. These include:

1. The production and appropriate, distribution of genderspecific information on back pain, mental health and nutrition in addition to gynaecological complaints, to all women seafarers.

2. The introduction of means for disposing of sanitary waste for all female crew on all ships.

3. Improved availability of female specific products e.g. sanitary products in port shops and welfare centres worldwide.

For any interventions to be effective it is vital that all of the main stakeholders - ship owners, manning agents, welfare organisations and of course the seafarers themselves, are engaged in the process. Many of these recommendations mirror those made by the ITF in their recent publication as referenced earlier.

In addition, by highlighting a few specific areas to shipping companies and manning agents, with the support of 
seafarers and the welfare organisations, we can encourage them to develop and implement policies on:

- medical confidentiality;

- sanitary waste;

- management of stress and other mental health issues e.g. exercise programmes, recreational facilities;

- the provision and appropriate distribution of health information.

Moving forward it may be worthwhile to extend this study to include more women seafarers or to include men and women working at sea, so as to compare and contrast their health and welfare needs. However this will require project management and funding and is beyond the remit of the current collaborative work. Other areas to study could include more detail regarding the cause of perceived health problems e.g. stress, back pain and how these issues may best be addressed.

It would also be beneficial to further address the issue of a lack of confidence in the medically trained staff on board. This is an issue for women seafarers on ships with officers trained to deliver medical care and on those with trained medical professionals.

The issue of sexual harassment is another area that must be highlighted. Further comment and analysis is beyond the scope of this survey but we do feel there is the definite need for additional study of this issue.

We hope to discuss these findings and ways in which the industry can move forward in this area at a briefing meeting of all interested parties to be held in London in September. Further details are available from: Caitlin Vaughan, Project Manager, ISWAN at: caitlin.vaughan@iswan.org.uk

\section{CONFLICT OF INTEREST}

The authors have no conflict of interest to declare.

\section{REFERENCES}

1. Hansen HL, Jensen J. Female seafarers adopt high risk lifestyle of male seafarers. Occupat Environmental Med 1998; 55: 49-51.

2. European Agency for Safety and Health at Work (n.d.) Risks and Trends in the Safety and Health of Women at Work. Report available at: http://www.lhc.org.uk/wp-content/uploads//2012/03/ women_at_work-summary.pdf (last accessed April 2015).

3. Belcher P, Sampson H, Thomas M, Veiga J, Zhao M. Women Seafarers - Global Employment Policies and Practices. International Labour Office, Geneva 2003.
4. Momoko K. Women Seafarers and their Identities, PhD Thesis, Cardiff University 2010.

5. Momoko K Code of behaviour at sea: women seafarers identity management. WMU J Maritime Affairs 2012; 12: 213-227.

6. Minghua Z. Women Seafarers in the EC: A Preliminary Report based on German and UK Case Studies. Cardiff: Seafarers International Research Centre 1998.

7. Thomas M. Get yourself a proper job girlie! Recruitment, retention and women seafarers. Maritime Policy and Management 2004; 31: 309-318.

8. Jiunn-Liang G, Gin-Shuh L. Sailing into rough seas: Taiwan's women seafarers' career development struggle. Women's Studies International Forum 2012; 35: 194-202.

9. Momoko K. Risking marriage and family: the maintenance of women seafarers' gender identities. The $1^{\text {st }}$ SIRC - Nippon Fellow Maritime Conference: Maritime Matters in the $21^{\text {st }}$ Century 22 January, 2009.

10. Dragomir C, Surugiu F. (n.d.) Seafarer women - perceptions of the seafaring career'. Conference proceedings paper. Advances in Fiscal, Political and Law Science.

11. Jiunn-Liang G, Gin-Shuh L. Sailing into rough seas: Taiwan's women seafarers' career development struggle'. Women's Studies International Forum 2012; 35: 194-202.

12. IMO's efforts to promote the participation of women in shore and sea-based posts align with the United Nation's Millennium Development Goal (2000) number 3: "promote gender equality and empower women'.

13. IMO. Information Paper on WMU Women's Association, TC 65/INF. 4, Technical Cooperation Committee $65^{\text {th }}$ session, 2015, Agenda item 9.

14. http://www.itfglobal.org/en/transport-sectors/seafarers/in-focus/ women-seafarers/(last accessed April 2015).

15. http://www.itfseafarers.org/ITI-women-seafarers.cfm (last accessed April 2015).

16. Alderton T, Bloor M., Kahveci E et al. The Global Seafarer: Living and Working Conditions in a Globalized Industry. International Labour Office, Geneva 2004.

17. Sulpice G. Study on EU seafarers' employment: final report. European Commission, Directorate-General for Mobility and Transport, Directorate C - Maritime Transport, 2011.

18. http://www.bles.dole.gov.ph/PUBLICATIONS/Current\%20Labor\%20 Statistics/HTML/table\%20of\%20contents.html (last accessed April 2015).

19. http://www.ttglobal.org/media/819789/hiv survey.pdf (last accessed June 2015).

20. Acejo I, Sampson H, Turgo N, Wadsworth E. The health and self-medication practices of seafarers', SIRC Symposium, Cardiff University, 6-7 July, 2011.

21. McKay S, Wright T. Seafarers in a global world: the changing needs of seafarers for advice, support and representation', WLRI Working Paper 3, London Metropolitan University, 2007. 


\section{APPENDIX 1. ONLINE SURVEY}

\section{Women Seafarers' Health Survey}

\section{Introduction}

This survey, aimed at women seafarers only, follows on from the Rapid Health Needs Questionnaire (pilot study) which was distributed in July 2014. The survey is fully confidential and has been devised by the International Transport Workers' Federation (ITF), Seamen's Hospital Society (SHS), International Maritime Health Association (IMHA) and International Seafarers' Welfare and Assistance Network (ISWAN).

The purpose of this survey is to help inform the way our organisations make or campaign for improvements to the health information/services available to women seafarers. It is designed to reach a much larger number of participants than the pilot study and to build on the findings we have so far. If you have already taken part in the first questionnaire, you are still encouraged to complete this one.

All responses are anonymous and cannot be traced back to you.

Please note this survey is aimed at women seafarers only.

\section{*1. Can you confirm you are a woman}

$\bigcirc$ Yes

No

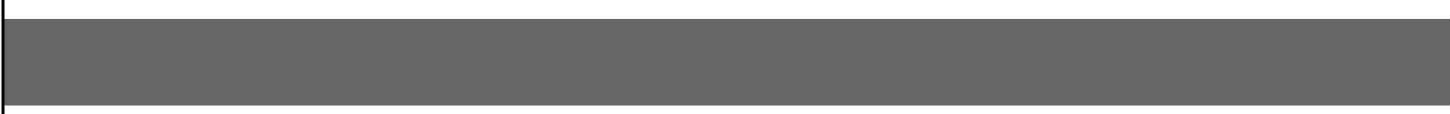

\section{*2. Please select your age group}

(19-30

$31-40$

४41-50

○1-60

$60+$

\section{*3. What is your Nationality?}

Philippines

India

Indonesia

O UK

Ousa

Other (please specify) 


\section{Women Seafarers' Health Survey}

\section{* 4. Which sector of the shipping industry do you work in?}

$\bigcirc$ Cruise/passenger ship

Cargo ship

Perry service

Fleet Auxiliary

(Tanker

Other (please specify)

*5. What department do you work in?

$\bigcirc$ Deck

Engine

Accommodation

Bar

$\bigcirc$ Restaurant

$\bigcirc$ Galley

Hotel/Reception/Administration

Medical

other (please specify)

*6. Are you an Officer or Crew/Ratings?

officer

crew/Ratings
*7. Is supervision of others part of your job role?
$\bigcirc$ Yes
No 


\section{Women Seafarers' Health Survey}

* 8. Please select the top three health challenges you face

$\square$ Joint pain or back pain

$\square$ Overweight/obesity

Stress/depression/anxiety

$\square$ Heavy/painful periods

$\square$ Sexual/reproductive health

$\square$ Alcohol overuse

$\square$ Headache

High blood pressure

$\square$ Quitting smoking

$\square$ I do not have any health challenges

$\square$ Other (please specify)

*9. Do you think any of these health challenges are related to your work?

$\bigcirc$ Yes

No

Idon't know

N/A

*10. Are there any issues that prevent you from accessing healthcare on board or in port?

$\square$ Cultural/religious beliefs

$\square$ Cannot access female doctor

$\square$ Concerns about lack of confidentiality on board the ship

Don't know how to find a doctor in port

$\square$ Lack of confidence in the ability of cruise ship doctor or medical officer

Fear - not ready to face health issues

I do not know what my health needs are

$\square$ cost

Transportation in port

$\square$ No issues

Other (please specify) 


\section{Women Seafarers' Health Survey}

*11. What would encourage you to access healthcare on board or in port?

Information on how to access health care

Transportation in port

Female doctor

Guaranteed confidentiality

A better understanding of my health needs

Health information

I don't know

Other (please specify)

*12. What types of health screenings/information/services do you think is needed to keep you healthy?

$\square$ Blood pressure information

Information on back/joint pain

Nutrition information

Quitting smoking programmes

Dental screenings

Mental health/depression advice

Vaccinations/immunisations

Sexual health disease checks

Easily accessible female/male condoms

Weight loss information

Routine wellness checks

Other (please specify)

*13. How do you like to learn about health?

Listening to health professionals

Reading leaflets, booklets

Through friends on social media

Online, Apps, Websites

Other (please specify) 


\section{Women Seafarers' Health Survey}

*14. Are there sanitary bins available in the toilet on board?

$\bigcirc$ Yes

$\bigcirc$ No

Comment

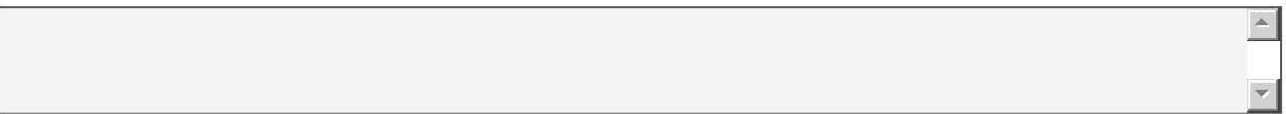

15. Is sexual harassment currently an issue for you?

Yes

$\bigcirc$ No

Comment

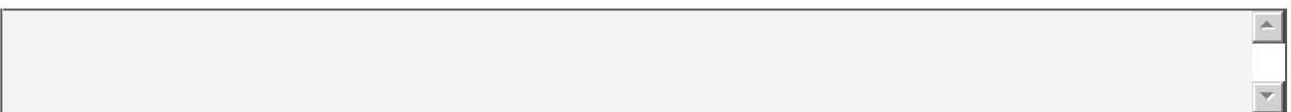

16. Do you have any other comments?

APPENDIX 2. FOCUS GROUP QUESTIONS/TOPICS

1. How did you find the survey?

2. Joint and back pain

3. What does good health mean to you?

4. When you think about good health, what type of image do you see?

5. What prevents you from accessing health care on board?

6. What might help you overcome these issues?

7. Do you try alternative medicines before seeing the ship doctor?

8. How do you think we could promote good health to females on ships? (Word of mouth, apps, booklets, women's health groups on ships?)

9. Any other comments. 